\title{
Analysis and Forecasting of the Energy Consumption in Wastewater Treatment Plant
}

\author{
ZhenHua Li, ${ }^{1}$ ZhiHong Zou $\mathbb{D}^{1,2}$ and LiPing Wang ${ }^{1}$ \\ ${ }^{1}$ School of Economics and Management, Beihang University, Beijing 100191, China \\ ${ }^{2}$ Beijing Key Laboratory of Emergency Support Simulation Technologies for City Operation, Beijing 100191, China
}

Correspondence should be addressed to ZhiHong Zou; zouzhihong@buaa.edu.cn

Received 2 April 2019; Revised 13 June 2019; Accepted 3 July 2019; Published 22 July 2019

Academic Editor: Andras Szekrenyes

Copyright (C) 2019 ZhenHua Li et al. This is an open access article distributed under the Creative Commons Attribution License, which permits unrestricted use, distribution, and reproduction in any medium, provided the original work is properly cited.

\begin{abstract}
Wastewater treatment plant (WWTP) is the energy-intensive industries. Energy is consumed at every stage of wastewater treatment. It is the main contributor to the costs of WWTP. Analysis and forecasting of energy consumption are critical to energy-saving. Many factors influence energy consumption. The relationship between energy consumption and wastewater is complex and challenging to identify. This article employed the fuzzy clustering method to categorize the sample data of WWTP and analyzed the relationship between energy consumption and the influence factors in different categories. The study found that energy efficiency in various categories was changed and the same influence factors in different types had different influence intensity. The Radial Basis Function (RBF) neural network was used to forecast energy consumption. The data from the complete set and categories was adopted to train and test the model. The results show that the RBF model using the date from the subset has better performance than the multivariable linear regression (MLR) model. The results of this study provided an essential theoretical basis for energy-saving in WWTP.
\end{abstract}

\section{Introduction}

Wastewater treatment plant (WWTP) is the energy-intensive industries. Collecting, treating, and discharging wastewater to acceptable permit standards needs a large amount of energy. Wastewater includes three stages. Physical treatment is used to remove the suspended solids and other impurities. Around $25 \%$ of energy is consumed to drive the influent pumps and aerated grit chamber [1]. Biological treatment is used to process high concentrations of organic matter and nitrogen. More than $90 \%$ of chemical oxygen demand (COD) and $20 \%$ nitrogen in wastewater is removed. Aerobic digestion and anaerobic digestion convert organic matter into carbon dioxide, nitrogen, methane, and so on. Much of the energy used by this stage is for aeration. Only a small amount of energy is used for pumping water. About $60-70 \%$ of energy is used in biological treatment [2]. Besides, sludge thickening and dewatering contribute $4.1-13.9 \%$ of the total energy consumption in WWTP [3]. The energy efficiency of WWTP is influenced to a great extent by the wastewater treatment technology, the size of the plant, and the sewage inflow and effluent quality [4]. Energy efficiency measure and treatment process modifications may be able to reduce their energy cost by up to $30 \%$ [5]. Studies to understand the energy consumption are critical to implementing target strategies for energy reduction.

It is clear that an improvement in energy efficiency enables the achievement of the same result with less energy or achieving an improved performance with the same power. Wastewater treatment is a nonlinear biological reaction process. The relationship between wastewater and energy consumption is complex and uncertain. The data analysis seems a difficult task because the data are multidimensional, complex, and nonlinear. In the scientific literature, there are a large number of studies on energy consumption in WWTP. Deborah et al. employed a multistep methodology to evaluate the energy efficiency of wastewater treatment in Italy and suggested some energy optimization solutions to decrease energy cost [6]. Daw et al. concluded that the energy audit could help to improve energy efficiency in wastewater treatment [7]. Viktoria et al. identified that energy consumption is decreasing with the increase of the amount of treated wastewater [8]. Ortiz et al. applied the life cycle assessment to evaluate water treatment technologies. They found that 
tertiary treatment did not increase the environment loads significantly [9]. Gua et al. analyzed the overall influence factors of energy use in WWTPs [10]. Abusoglu et al. used the thermoeconomical methodology to assess a municipal wastewater treatment system. [11]. Plappally and Lienhard considered the wastewater treated with various processes, and the results showed that membrane bioreactors were significant energy consumers in wastewater treatment [12]. The energy intensity of advanced wastewater treatment process is higher than the traditional method. Hernández-Sancho et al. employed the nonradial DEA model for estimating the energy efficiency in Spanish wastewater treatment plant, and results showed that the energy efficiencies of the analyzed WWTPs were quite low [13]. Awe et al. discussed the energy production, usage, and saving in WWTP [14]. Andersson and Holmberg showed that electrical energy consumption decreased by $10 \%$ by introducing an in-feed filter system for the blowers [15]. Joao and Justina found that energy saving of every WWTPs could vary from $20 \%$ up to $40 \%$ [16]. Also, some scholars provide a review of the various modeling techniques for modeling the wastewater treatment process [17-20]. Xu et al. employed the artificial immune algorithm to calculate the optimal setting value of the control variables [21]. Ye et al. combined the RBF network and immune algorithm to establishing the wastewater treatment process models [22]. Guan et al. and Wang et al. proposed the soft-sensing method for predicting the quality parameters of wastewater treatment $[23,24]$. Luo et al. developed a soft computing approach based on the back propagation neural networks and fuzzy-rough sets to predict effluent $\mathrm{NH}_{3}-\mathrm{N}$, $\mathrm{COD}$, and total nitrogen (TN) concentration of a real WWTP [25]. The results showed that the prediction by this approach was better than the other traditional modeling approaches. Chen et al. proposed a hierarchically neural network to predict the COD and biochemical oxygen demand (BOD) concentrations [26]. Yu et al. implemented the statistical regression models to predict energy consumption in WWTP [27]. Systematic analysis of energy efficiency and modeling of the energy consumption in wastewater treatment under various categories is somewhat rare in the literature.

As wastewater treatment system contains many statistics about energy consumption, and FCM is an efficient tool to divide a given set of data into categories so that elements drawn from the same type are as similar to each other as possible, while those assigned to different groups are dissimilar [28]. FCM has been widely used in economics, finance, science, and other fields and has obtained lots of good results [29-32]. However, few studies have paid attention to the application of FCM in analyzing energy consumption in WWTP. The energy efficiency in different categories should be considered. Thus, clustering analysis appears to be an appropriate choice for categorizing energy efficiency with similar energy consumption and facilitating the exploration of the specific characteristics of each category and its influence factors. The Radial Basis Function (RBF) neural network was adopted to establish an energy consumption model. The central sample point is critical for the performance of the RBF model. Often only the nearest sample point plays a vital role, while the other samples far from the spot have very minimum impact, which can be ignored. Here, the RBF model used data from a complete set and subset, respectively, to establish the prediction models. The multivariable linear regression (MLR) model was also used. The results showed that using the data from the categories can improve the performance of these models. The method could be used by wastewater managers to accurately forecast the behavior of the energy consumption in various WWTPs.

\section{Methodology and Data}

The energy consumption of WWTPs is ambiguous and uncertain. It is influenced by many factors and involves three standard process performance indicator variables that are regarded as input parameters: Influent loads, COD, and, $\mathrm{TN}$ removals. The energy efficiency in different condition should be considered. Thus, clustering analysis appears to be an appropriate choice for categorizing energy efficiency with similar energy consumption characteristics. This paper selects the FCM method to analyze the energy consumption in WWTP.

2.1. The FCM Method. The FCM method was first proposed by Dunn and Bezdek in the 1980s [28]. It has been applied in many fields. FCM can be described as below. Given subsets $X=\left\{X_{1}, X_{2}, \ldots, X_{N}\right\}$, where $X_{k}=\left(x_{k 1}, x_{k 2}, \ldots, x_{k n}\right)^{T} \in$ $R^{n}, x_{k j}(j=1,2, \ldots, n)$ is the $j$ th element of a sample $X_{k}(k=$ $1,2, \ldots, N) . Z^{T}=\left(Z_{1}, Z_{2}, \ldots, Z_{c}\right)\left(Z_{i}=\left(z_{i 1}, z_{i 2}, \ldots, z_{\text {in }}\right)^{T} \epsilon\right.$ $\left.R^{n}\right)$ is the cluster centers vector. The fuzzy c-clustering for $X$ can be described as below:

$$
\begin{aligned}
& \min \quad J_{m}(\mathrm{U}, Z, c)=\sum_{i=1}^{c} \sum_{k=1}^{N} \mu_{k}^{h} d_{i k}^{2} \\
& =\sum_{k=1}^{N} \sum_{i=1}^{c} \mu_{k}^{m}\left\|X_{k-} Z_{i}\right\|^{2}, \quad 1 \leq m \leq \infty \\
& \sum_{i=1}^{c} \mu_{i k}=1, \quad(1 \leq k \leq N) \\
& 0<\sum_{k=1}^{N} \mu_{i k} \leq N, \quad i=1,2, \ldots, c . \\
& \mu_{i k}=\left(\sum_{j=1}^{c}\left(\frac{\left\|X_{i-} Z_{k}\right\|}{\left\|X_{j-} Z_{k}\right\|}\right)^{2 /(m-1)}\right)^{-1} \\
& Z_{k}=\frac{\sum_{k=1}^{n}\left(\mu_{i k}^{m} X_{k}\right)}{\sum_{k=1}^{n}\left(\mu_{i k}^{m}\right)}
\end{aligned}
$$

where $U=\left[\mu_{i k}\right]\left(0 \leq \mu_{i k} \leq 1,1 \leq i \leq c, 1 \leq k \leq\right.$ $N)$ is partition matrix. $Z=\left[Z_{i}\right]$ is the nuclear matrix of clustering. $\mu_{i k}$ is the fuzzy membership grade belonging to the $k$ th category of the ith sample. $\mathrm{d}_{\mathrm{ik}}^{2}$ denote the distance function between $i$ th element and $k$ th cluster center in the same subset. $m$ is the weighted index, usually set to 2 . The values of the original data must be normalized to the same 


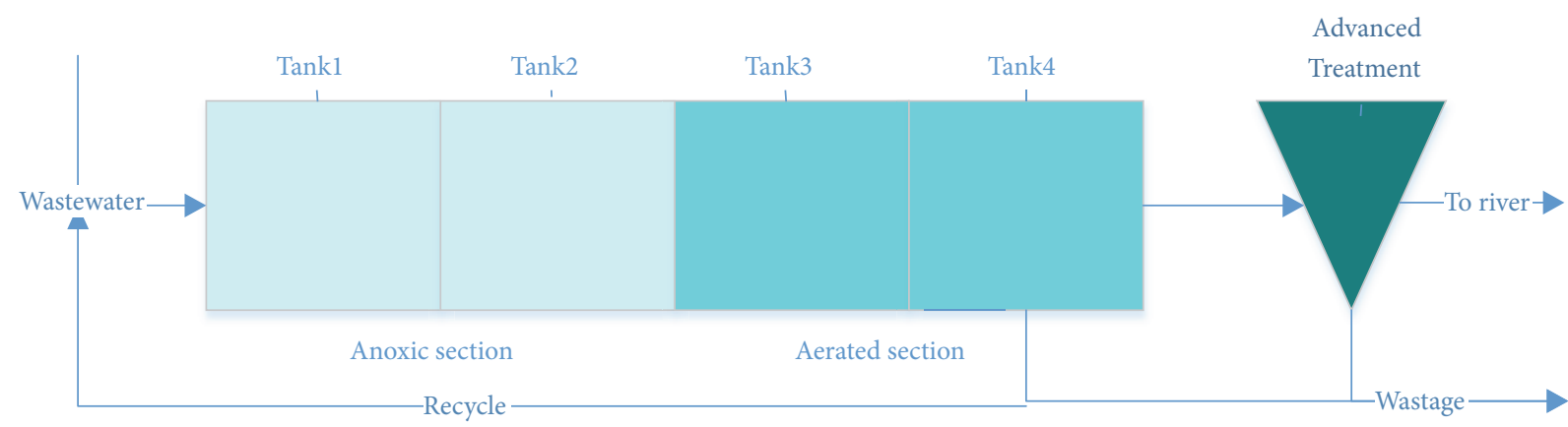

FIGURE 1: Modified the process of the WWTP system (Tank 1-2. Anaerobic section. Tank 3-4 Aerated sections).

order as the inaccurate cluster will be induced by the order variation of the data characterizing the factors. The procedure of fuzzy c-clustering algorithm is as follows.

Step 1. Determine the cluster number and the cluster center; initialize the partition matrix.

Step 2. Calculate the nuclear matrix of clustering.

Step 3. Update the partition matrix.

Step 4. For each partition matrix, compare the matrix norm with its previous value.

Step 5. If the stopping iteration condition is not met, loop to Step 2.

The FCM parameter values were set as follows: the maximum number of iterations is 40 ; the weighted index is 4 ; the cluster number is 3 .

2.2. Radical Basis Function (RBF) Neural Networks. Wastewater treatment is a highly nonlinear dynamic process. It is complicated and influenced by many factors. The relationship between energy consumption and influencing factors is nonlinear and complex. Meanwhile, the influent loads and the concentration of contaminations in the sewage are constant change. It is difficult to obtain reliable parameters of many biochemical reactions and fit a reasonable energy consumption model. Owing to many uncertain factors affecting energy consumption in WWTP, the energy consumption systems undergo nonlinear system changes dynamically. Neural networks played an important role in solving these problems. The model has been widely applied to various fields of mathematics, engineering, economics [22, 33, 34]. It can model any nonlinear system to a high degree of accuracy by adjusting the network parameters and uses the steepest descent method to search for the optimal solution. It includes the input layer, the hidden layer, and an output layer. Each sheet contains a massive parallel distributed neuron. The network can acquire the knowledge and modify the synaptic weights to attain the desired design objective in the learning process. Here, the RBF neural networks were introduced to forecast energy consumption in WWTP. Three leading performance indicators of WWTP, influent loads, COD, and
TN removals were chosen as the input of these models. The distribution density of the RBF network is 0.3 .

2.3. Data Sources. The data in this paper was collected from the daily records of a municipal WWTP located in Jimei District, Xiamen, China. The data includes 360 samples (from 25th December 2015 to 24th December 2016) after removing six invalid samples. The WWTP applies the activated sludge process, treating municipal sewage. The plant has a design capacity of 90000 cubic meters per day, or nominally 560,000 equivalent population. The inflow loads are 5390095200 cubic meters per day. Figure 1 depicts the operation of the WWTP system. The first two reactions are anoxic section, followed by two aeration sections and the clarifier. The effluent quality meets the national integrated discharge standard. The statistical describes energy consumption and influencing factors are depicted in Table 1 . Table 1 describes energy consumption, inflow load, COD removal, and total nitrogen removal.

\section{Results and Discussion}

The energy consumption of WWTP could be depicted by three indicators: inflow loads, COD, and TN removals. The present study selected these indicators as the clustering index to analyze the energy consumption of WWTP. The energy consumption of this WWTP was determined into three clusters with its significant characteristic. Figure 2 shows the scatter diagram of energy consumption in different categories. Table 2 shows the center of different groups. The partial correlation coefficient among energy consumption and the influencing factors in different types are depicted in Table 3.

3.1. Clustering Results. The electricity consumption per cubic meter wastewater in the center of the first category is 0.2907 $\mathrm{kWh} / \mathrm{m}^{3}$. This category contains 159 sets of data. As it can be seen in Table 3, the partial correlation coefficients of the influencing factors are $0.226,0.374$, and 0.283 , respectively. The results show that COD removal has a significant impact on energy consumption, followed by total nitrogen removal, while inflow loads. 
TABLE 1: Statistical description of the energy consumption parameters.

\begin{tabular}{lcccc}
\hline Unit & $\begin{array}{c}\text { Inflow loads } \\
\left(10^{4} \times \mathrm{m}^{3}\right)\end{array}$ & $\begin{array}{c}\text { COD removal } \\
(\text { tons })\end{array}$ & $\begin{array}{c}\text { Total nitrogen removal } \\
\text { (tons })\end{array}$ & $\begin{array}{c}\text { Energy consumption } \\
(\mathrm{kWh})\end{array}$ \\
\hline 1 & 7.48 & 17.27 & 2.08 & 21177 \\
2 & 7.09 & 13.39 & 2 & 20085 \\
3 & 7.18 & 16.37 & 1.99 & 20729 \\
4 & 7.08 & 16.63 & 2.11 & 20688 \\
5 & 7.01 & 11.14 & 2.06 & 20906 \\
$\ldots$ & $\ldots$ & $\ldots$ & $\ldots$ & 23975 \\
355 & 8.43 & 20.58 & 3.17 & 23762 \\
356 & 8.28 & 20.29 & 2.87 & 24933 \\
357 & 8.5 & 10.8 & 3.03 & 24110 \\
358 & 8.66 & 35.58 & 2.56 & 23983 \\
359 & 8.53 & 8.35 & 1.38 & 2.08 \\
360 & 8.05 & 17.87 & 2.08 & 2 \\
\hline
\end{tabular}

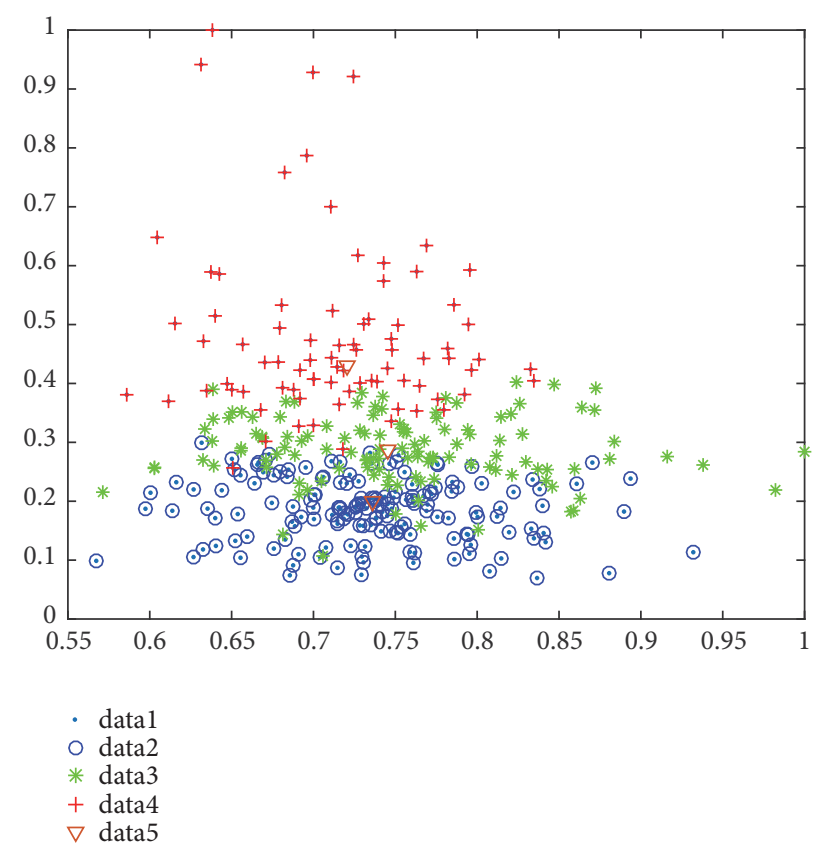

Figure 2: Scatter diagram of energy consumption in different categories.

TABLE 2: The center of different categories.

\begin{tabular}{cccc}
\hline Center & Inflow loads & COD removal & Total nitrogen removal \\
\hline Index 1 & 0.7365 & 0.2009 & 0.2534 \\
Index 2 & 0.7451 & 0.2857 & 0.4307 \\
Index 3 & 0.7209 & 0.4308 & 0.3798 \\
\hline
\end{tabular}

The electricity consumption per cubic meter wastewater in the center of the second category is $0.2942 \mathrm{kWh} / \mathrm{m}^{3}$. This category contains 121 sets of data. It can be seen in Table 3 that the partial correlation coefficients of the influencing factors are $0.338,0.516$, and 0.575 , respectively. Total nitrogen removal is positively contributing to energy consumption followed by COD removal, while inflow loads.

The electricity consumption per cubic meter wastewater in the center of the third category is $0.2844 \mathrm{kWh} / \mathrm{m}^{3}$. This category contains 80 sets of data. As it can be seen in Table 3, the partial correlation coefficients of the influencing factors are $0.517,0.323$, and 0.355 , respectively. The results show that energy consumption is highly correlated with inflow loads, followed by total nitrogen removal, while COD removal.

The statistical description of energy consumption and influencing factors in different categories are depicted in Table 4. It can be seen that average electricity consumption per cubic meter and inflow loads of three clusters are almost the same. COD removal and total nitrogen removal vary greatly. The COD removal of the first category is nearlyl.63 times of the second category and 2.79 times of the third category. The total nitrogen removal of the first category is 1.27 times of second category and 1.69 times of the third category. The energy consumption of the first category achieves improved performance with the same energy consumption. It has better performance than other groups. The results indicate that when inflow loads are stable, COD removal and total nitrogen removal have a weak impact on energy consumption. Effective removal of the COD and total nitrogen are essential for improving the energy efficiency of this WWTP.

It can be seen in Table 3 that efficient removal COD and total nitrogen can improve the energy efficiency of the second category. In the third category, inflow loads play a prominent role in energy consumption and as is shown in Table 3, efficient treating inflow loads are essential for the high energy efficiency of this category.

The above results indicate that the energy efficiency of WWTP in the different categories is different. Energy efficiency has an excellent performance when a lot of COD and total nitrogen are removed. Energy efficiency has poor performance when COD and total nitrogen removal are poor. 


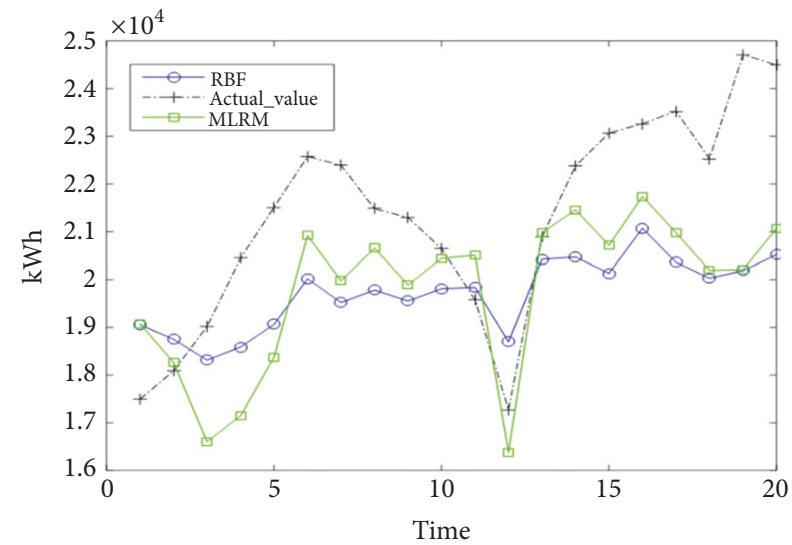

(a)

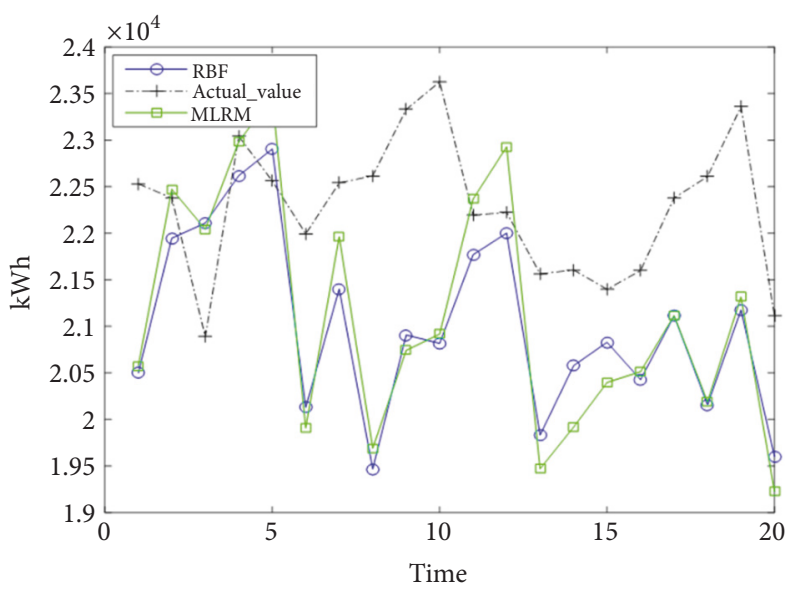

(c)

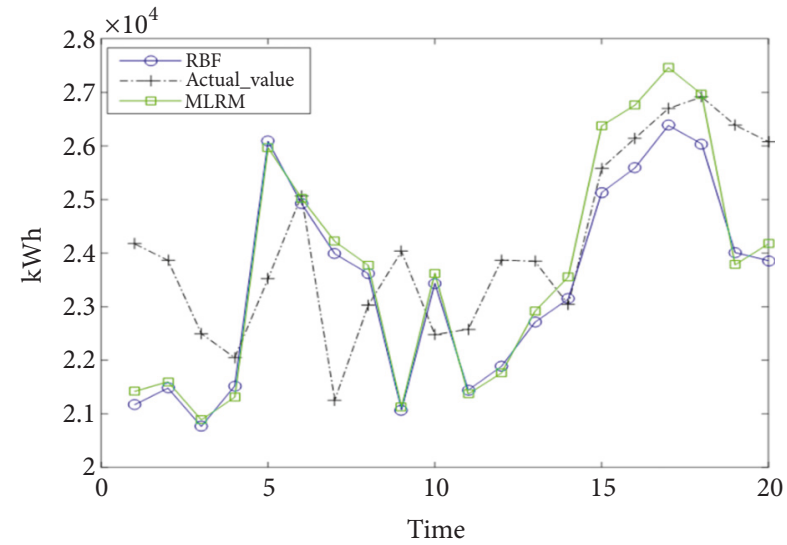

(b)

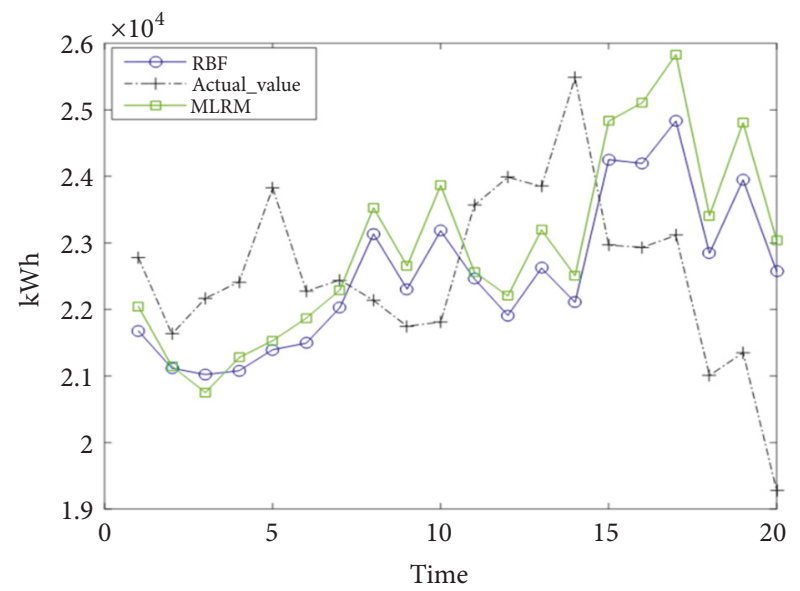

(d)

FIgURE 3: The actual value and forecasting value under different data set.

TABLE 3: The partial correlation coefficient among energy consumption and the influencing factors in different categories.

\begin{tabular}{lcccc}
\hline & Pearson Correlation & Inflow loads & COD removal & Total nitrogen removal \\
\hline Index1 & Energy consumption & 0.226 & 0.374 & 0.283 \\
& Sig. (2-tailed) & 0.004 & 0.000 & 0.000 \\
Index2 & Energy consumption & 0.338 & 0.516 & 0.575 \\
& Sig. (2-tailed) & 0.000 & 0.000 & .000 \\
Index3 & Energy consumption & 0.517 & 0.323 & 0.355 \\
& Sig. (2-tailed) & 0.000 & 0.004 & 0.001 \\
\hline
\end{tabular}

TABLE 4: Statistical description of energy consumption and influencing factors in different categories.

\begin{tabular}{|c|c|c|c|c|c|c|}
\hline & \multirow[b]{2}{*}{ Mean } & \multirow{2}{*}{$\begin{array}{c}\text { Index1 } \\
\text { Std. Deviation }\end{array}$} & \multirow{2}{*}{$\begin{array}{l}\text { Index2 } \\
\text { Mean }\end{array}$} & \multicolumn{3}{|c|}{ Index3 } \\
\hline & & & & Std. Deviation & Mean & Std. Deviation \\
\hline Energy consumption (kWh) & 22452 & 1790. & 22577 & 1965 & 21483 & 1738 \\
\hline Inflow loads $\left(10^{4} \mathrm{~m}^{3}\right)$ & 7.751 & 0.560 & 7.626 & 0.693 & 7.645 & 0.628 \\
\hline COD (tons) & 20.824 & 8.181 & 12.716 & 3.379 & 7.463 & 1.932 \\
\hline TN (tons) & 2.215 & 0.398 & 1.747 & 0.433 & 1.309 & 0.397 \\
\hline Average electricity consumption $\left(\mathrm{kWh} / \mathrm{m}^{3}\right)$ & 0.2897 & & 0.2961 & & 0.2810 & \\
\hline
\end{tabular}




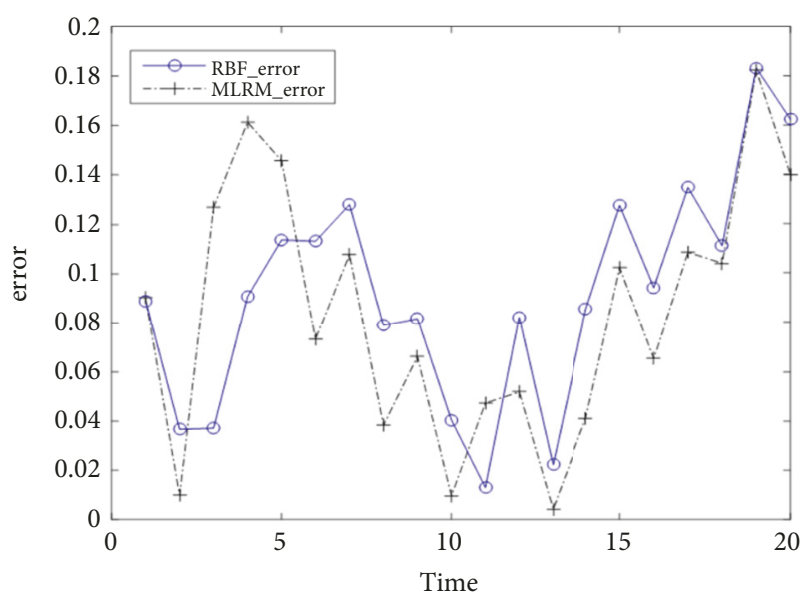

(a)

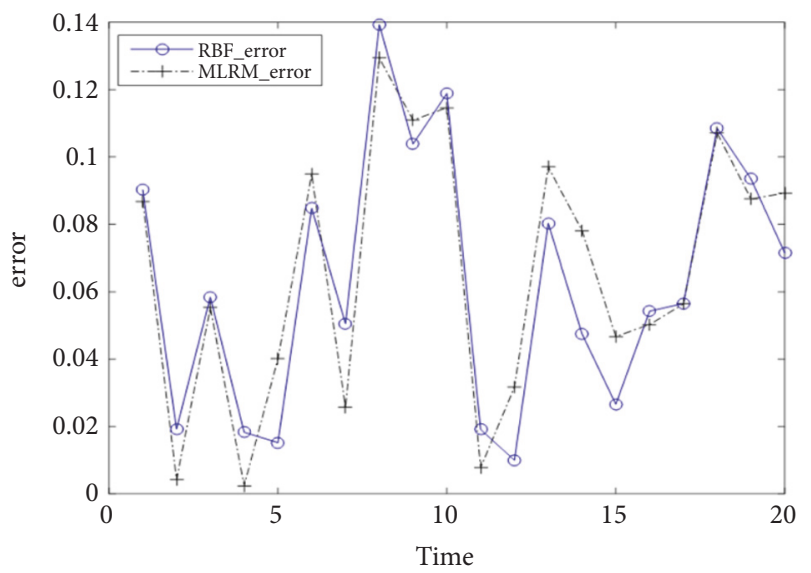

(c)

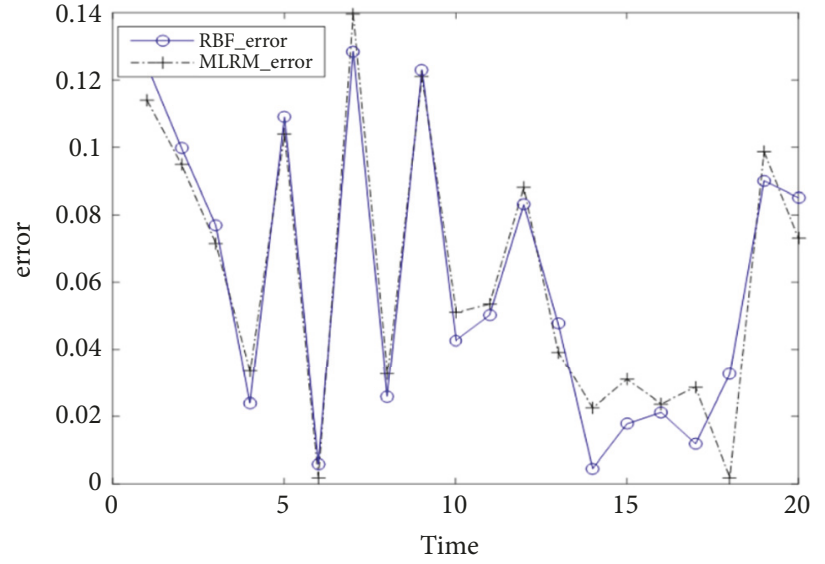

(b)

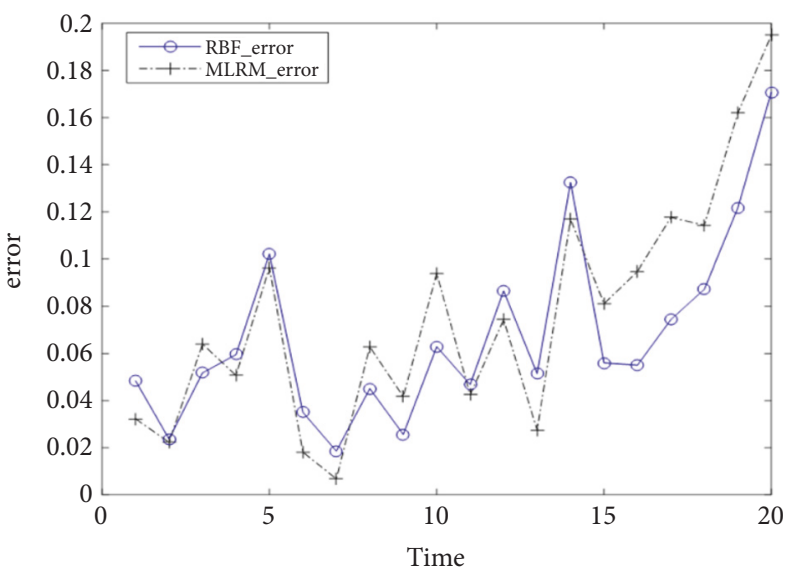

(d)

FIGURE 4: The relative error of the RBF model and multivariable linear regression model under different data set.

3.2. Forecasting Energy Consumption for WWTP. To compare the superiority of the RBF model and the MLR model in handling the data sets (the data sets were collected from the WWTP from the from 25th December 2015 to 24th December 2016) and subset (the clustering results), the 70 data were selected from these set. The first 50 data were used in the in-sample period. The data from 51 to 70 were used to evaluate the forecasting performance. The forecasting ability of the RBF model and the MLR model for different data set is compared in Table 5 and Figure 3. The relative errors of different data sets are shown in Figure 4.

As can be seen in Table 5, the min relative errors of the MLRM are lower than the RBF model. The max relative errors of the RBF model for different data set is $18.32 \%, 12.85 \%$, $13.97 \%$, and $17.08 \%$, respectively. The max relative error of the three categories is lower than the data set. The mean absolute percent error for the RBF model for various data set is $9.13 \%, 6.02 \%, 6.33 \%$, and $6.78 \%$, respectively. The mean absolute percent error of the RBF model for various data set is $9.13 \%, 6.02 \%, 6.33 \%$, and $6.78 \%$, respectively. The results show that the RBF model has better performance in three categories than in the data set. The mean absolute percent error of the MLRM model for various data set is $8.38 \%, 6.12 \%$,
$6.58 \%$, and $7.58 \%$, respectively. The outlet results show that the model has higher accuracy in three categories than in the data set. It means that using the clustering results can improve the performance of two forecasting models. According to Table 5, the empirical results indicate that the MLRM model data set has higher accuracy than the RBF model. However, for the three categories, the mean absolute percent error of the RBF model is lower than the values of the MLM model. Meanwhile, for the different categories, the forecasting effect of the RBF model is better than the MLM model.

\section{Conclusions}

In this article, it is attempted to analyze and predict energy consumption in WWTP. WWTP is the energy-intensive industries. Analysis and forecasting of energy consumption in WWTP are critical to energy-saving. The energy consumption of WWTP is a complex nonlinear system and influenced by many factors. A large amount of collected data is complex, multidimensional, and nonlinearly related. Therefore, the analysis and forecasting of energy consumption are a difficult task due to the characteristic of the data. This paper considered the direct energy use indexes related 
TABLE 5: The relative errors of the RBF model and the multivariable linear regression model under different sets.

\begin{tabular}{|c|c|c|c|c|c|c|}
\hline & \multicolumn{2}{|c|}{ Min relative error $(\%)$} & \multicolumn{2}{|c|}{ Max relative error $(\%)$} & \multicolumn{2}{|c|}{ MAPE (\%) } \\
\hline & MLRM & $\mathrm{RBF}$ & MLRM & $\mathrm{RBF}$ & MLRM & $\mathrm{RBF}$ \\
\hline The data set & 0.42 & 1.3 & 18.23 & 18.32 & 8.38 & 9.13 \\
\hline The first category & 0.18 & 0.46 & 13.95 & 12.85 & 6.12 & 6.02 \\
\hline The second category & 0.24 & 1.00 & 12.94 & 13.93 & 6.58 & 6.33 \\
\hline The third category & 0.68 & 1.85 & 19.5 & 17.08 & 7.58 & 6.78 \\
\hline
\end{tabular}

to energy consumption and employed the FCM method to divide these indexes into three clusters with their significant characteristic. The results show that the average electricity consumption per cubic meter wastewater in various categories has a slight difference. In the first category, the average electricity consumption can removal more COD and total ammonia than the other categories. It means that the energy efficiency of the first category has a better performance than other classes. The partial correlation coefficient was used to analyze the relationships between energy consumption and various influencing factors in different types. It can be discovered that the partial correlation coefficient in multiple groups is different. In the first category, COD removal is a significant factor affecting energy consumption. In other groups, nitrogen and inflow loads have a substantial effect on energy consumption. To remove more pollutions with the same energy, the WWTP can determine the wastewater into different clusters with its significant characteristic. According to the characteristics of sewage adjust the wastewater treatment process to deal with sewage. Besides, the WWTP should adopt new technology to improve energy efficiency. The RBF model and the MLRM model were employed to forecast energy consumption in WWTP for the different data set. The numerical experiment indicates that these models adopted the data from the different categories have better performance than the data set. Meanwhile, for the different groups, the forecasting effect of the RBF model is better than the MLM model. The clustering analysis is a technique to analyze the energy efficiency of WWTP. Meanwhile, use the data from the clustering results can improve the performance of the RBF model.

Wastewater industry faces the strict effluent limitations for removal of currently-unregulated contaminants in the future. To treat the influent to reduce these pollutions, WWTPs would become more energy-intensive. The WWTP should improve energy efficiency by applying new energyintensive technologies to handle wastewater. The results show here could offer references to improve the energy efficiency of WWTP.

\section{Data Availability}

All the data used in this paper are uploaded to the supplementary material.

\section{Conflicts of Interest}

The authors declare no conflicts of interest.

\section{Authors' Contributions}

Work presented here was conceived, carried out, and analyzed by Zhenhua Li, Zhihong Zou, and Liping Wang.

\section{Acknowledgments}

This work was supported by the National Natural Science Foundation of China (No. 51478025).

\section{Supplementary Materials}

The data in this paper were collected from the daily records of a municipal wastewater treatment plant, and there added up to 360 samples (from 25th December 2015 to 24th December 2016) after removing six invalid samples. The statistical describes energy consumption and influencing factors are depicted in Table 1. For each variable, the RBF model used the first 50 data as the in-sample period. The data from 51 to 60 was used to evaluate the forecasting performance. Table 1 describes energy consumption, inflow load, COD removal, and total nitrogen removal. (Supplementary Materials)

\section{References}

[1] K. Smith and S. M. Liu, "Energy for conventional water supply and wastewater treatment in urban china: a review," Global Challenges, vol. 1, no. 5, pp. 1-6, 2017.

[2] T. Xie and C. W. Wang, "Energy consumption in wastewater treatment plants in China," World Congress on water, Climate and Energy, vol. 34, no. 7, pp. 1-6, 2012.

[3] S. Chen and B. Chen, "Net energy production and emissions mitigation of domestic wastewater treatment system: A comparison of different biogas-sludge use alternatives," Bioresource Technology, vol. 144, pp. 296-303, 2013.

[4] Y. Jian, W. Fu, L. H. Mao et al., "Influence factors analysis of urban sewage treatment plant on energy consumption," Journal of Beijing Jiaotong University, vol. 38, no. 1, pp. 33-37, 2014.

[5] A. Stillwell, D. Hoppock, and M. Webber, "Energy recovery from wastewater treatment plants in the united states: a case study of the energy-water nexus," Sustainability, vol. 2, no. 4, pp. 945-962, 2010.

[6] D. Panepinto, S. Fiore, M. Zappone, G. Genon, and L. Meucci, "Evaluation of the energy efficiency of a large wastewater treatment plant in Italy," Applied Energy, vol. 161, pp. 404-411, 2016.

[7] J. Daw, K. Hallett, J. DeWolfe, and I. Venner, "Energy efficiency strategies for municipal wastewater treatment facilities," Tech. Rep. NREL/TP-7A20-53341, National Renewable Energy Laboratory, 2012. 
[8] V. Pitas, B. Fazekas, Z. Banyai, and A. Karpati, "Energy efficiency of the municipal wastewater treatment," Journal of Biotechnology, vol. 150, pp. 163-164, 2010.

[9] M. Ortiz, R. Raluy, and L. Serra, "Life cycle assessment of water treatment technologies: wastewater and water-reuse in a small town," Desalination, vol. 204, no. 1-3, pp. 121-131, 2007.

[10] Y. Gu, Y. Li, X. Li et al., "Energy self-sufficient wastewater treatment plants: feasibilities and challenges," Energy Procedia, vol. 105, pp. 3741-3751, 2017.

[11] A. Abusoglu, S. Demir, and M. Kanoglu, "Thermoeconomic assessment of a sustainable municipal wastewater treatment system," Journal of Renewable Energy, vol. 48, pp. 424-435, 2012.

[12] A. K. Plappally and J. H. Lienhard V, "Energy requirements for water production, treatment, end use, reclamation, and disposal," Renewable \& Sustainable Energy Reviews, vol. 16, no. 7, pp. 4818-4848, 2012.

[13] F. Hernández-Sancho, M. Molinos-Senante, and R. SalaGarrido, "Energy efficiency in Spanish wastewater treatment plants: A non-radial DEA approach," Science of the Total Environment, vol. 409, no. 14, pp. 2693-2699, 2011.

[14] A. Al-Wakeel, J. Wu, and N. Jenkins, "k -means based load estimation of domestic smart meter measurements," Applied Energy, vol. 194, pp. 333-342, 2017.

[15] R. Andersson and M. Holmberg, Energy conservation in wastewater treatment operation - A case study at Himmerfjarden WWTP [Master, thesis], IEA, Lund University, Sweden, 2006.

[16] J. Henriques and J. Catarino, "Sustainable value - An energy efficiency indicator in wastewater treatment plants," Journal of Cleaner Production, vol. 142, pp. 323-330, 2017.

[17] A. M. Ahmed, "Prediction of dissolved oxygen in Surma River by biochemical oxygen demand and chemical oxygen demand using the artificial neural networks (ANNs)," Journal of King Saud University-Engineering Sciences, vol. 29, no. 2, pp. 151-158, 2014.

[18] N. Clara, "Neural networks complemented with genetic algorithms and fuzzy systems for predicting nitrogenous effluent variables in wastewater treatment plants," WSEAS Transactions on Systems, vol. 7, no. 6, pp. 695-705, 2008.

[19] D. Wang, G. Wang, F. Yang, and C. Liu, "Treatment of municipal sewage with low carbon-to-nitrogen ratio via a novel integrated process," Chemical Engineering Journal, vol. 341, pp. 58-64, 2018.

[20] D. Ma, T. Zhou, J. Chen, S. Qi, M. Ali Shahzad, and Z. Xiao, "Supercritical water heat transfer coefficient prediction analysis based on BP neural network," Nuclear Engineering and Design, vol. 320, pp. 400-408, 2017.

[21] Y. G. Xu, Y. L. Song, F. Luo, and Y. T. Zhang, "Energysaving optimization of wastewater treatment system based on artificial immune algorithm," Journal of South China University of Technology, vol. 41, pp. 34-40, 2013.

[22] H. Ye, F. Luo, and Y. Xu, "Application of RBF network based on immune algorithm to predicting of wastewater treatment," in Advances in Neural Networks - ISNN 2009, Lecture Notes in Computer Science, pp. 1197-1202, Springer, Berlin, Germany, 2009.

[23] Q. Guan, W.-H. Wang, S.-Y. Chen, and X.-L. Xu, "A softsensing technique for wastewater treatment based on BP and RBF neural networks," in Proceedings of the 2005 International Conference on Neural Networks and Brain, ICNNB'05, pp. 121123, China, October 2005.
[24] W. L. Wang and M. Ren, "Soft-sensing method for wastewater treatment based on BP neural network," World Congress on Intelligent Control \& Automation, vol. 14, pp. 575-584, 2002.

[25] F. Luo, R.-H. Yu, Y.-G. Xu, and Y. Li, "Effluent quality prediction of wastewater treatment plant based on fuzzy-rough sets and artificial neural networks," in Proceedings of the Fourth International Conference on Fuzzy Systems and Knowledge Discovery, FSKD 2009, pp. 47-51, China, August 2009.

[26] Q. Chen, W. Chai, and J. Qiao, "Modeling of wastewater treatment process using recurrent neural network," in Proceedings of the 2010 8th World Congress on Intelligent Control and Automation, WCICA 2010, pp. 5872-5876, China, July 2010.

[27] Y. Yu, Z. Zou, and S. Wang, "Statistical regression modeling for energy consumption in wastewater treatment," Journal of Environmental Sciences, vol. 75, pp. 201-208, 2019.

[28] J. V. De Oliveira and W. Pedrycz, Advances in Fuzzy Clustering And Its Applications, Wiky Online Library, 2007.

[29] O. W. Awe, R. Liu, and Y. Zhao, "Analysis of energy consumption and saving in wastewater treatment plant: case study from ireland," Journal of Water Sustainability, vol. 6, pp. 63-76, 2017.

[30] T. F. Zhang, F. Lv, and R. Gu, "The influence on clustering results of electricity load curves using different distances," Applied Mechanics and Materials, vol. 401-403, pp. 1440-1443, 2013.

[31] C. S. Ozveren, C. Vechakanjana, and A. P. Birch, "Fuzzy classification of electrical load demand profiles - A case study," in Proceedings of the 5th International Conference on Power System Management and Control, pp. 353-358, UK, April 2002.

[32] W. Pedrycz, "Collaborative fuzzy clustering," Pattern Recognition Letters, vol. 23, no. 14, pp. 1675-1686, 2002.

[33] H.-T. Pao, "Forecasting electricity market pricing using artificial neural networks," Energy Conversion and Management, vol. 48, no. 3, pp. 901-912, 2007.

[34] Z. Yin, B. Jia, S. Wu, J. Dai, and D. Tang, "Comprehensive forecast of urban water-energy demand based on a neural network model," Water, vol. 10, pp. 1-16, 2018. 


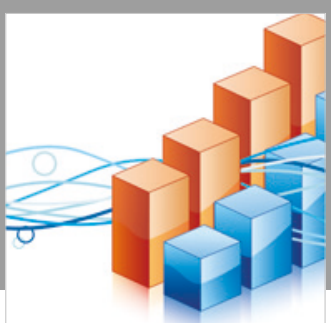

Advances in

Operations Research

\section{-n-m}
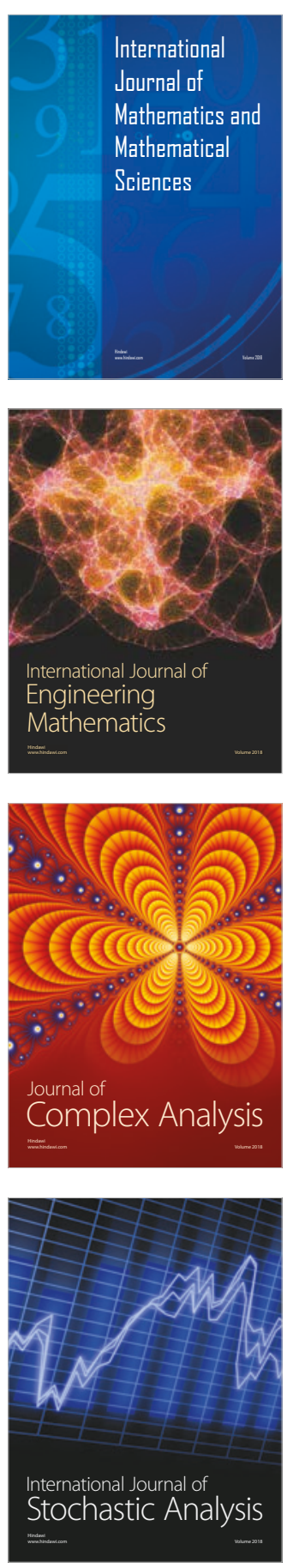
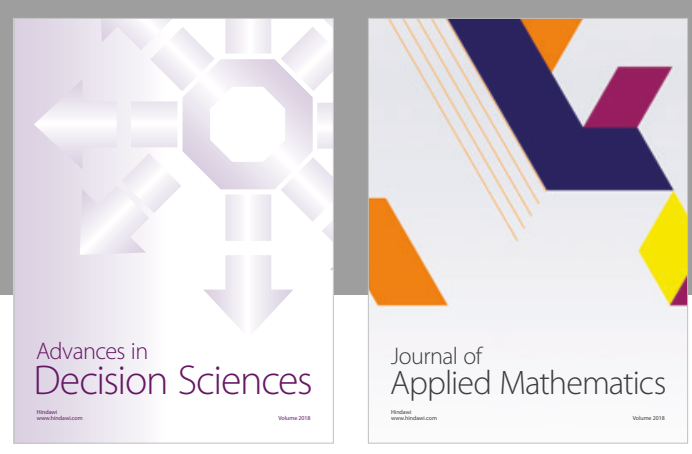

Journal of

Applied Mathematics
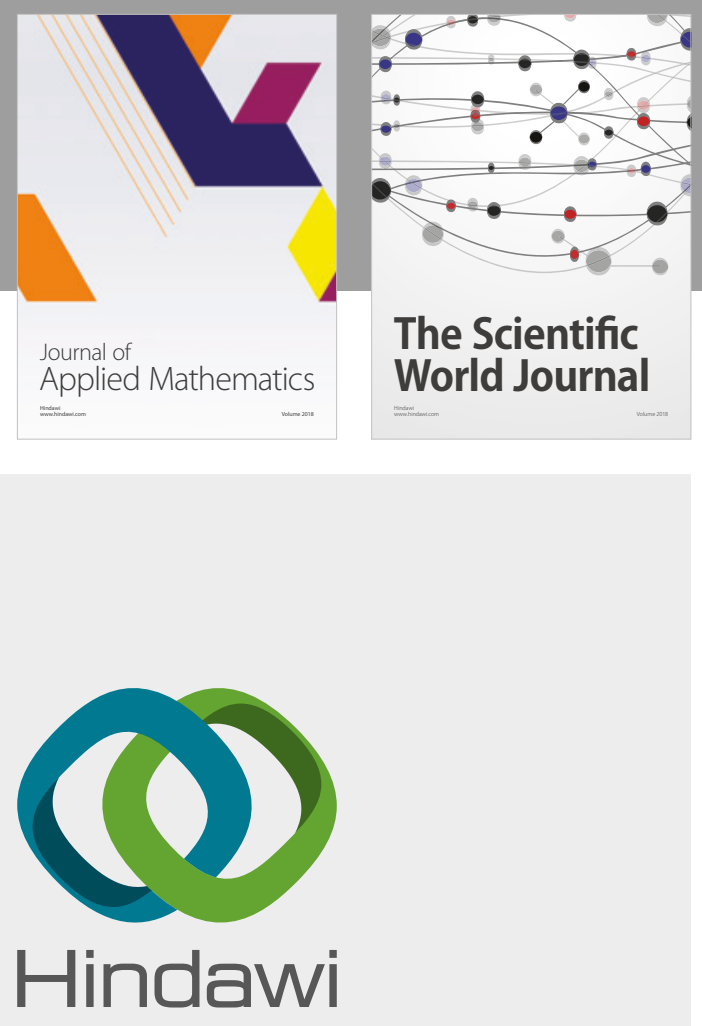

Submit your manuscripts at

www.hindawi.com

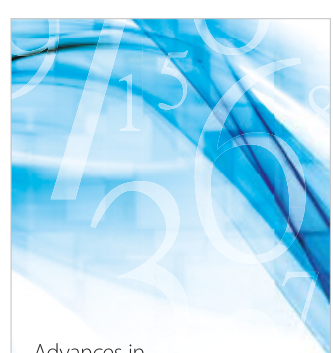

Advances in
Numerical Analysis
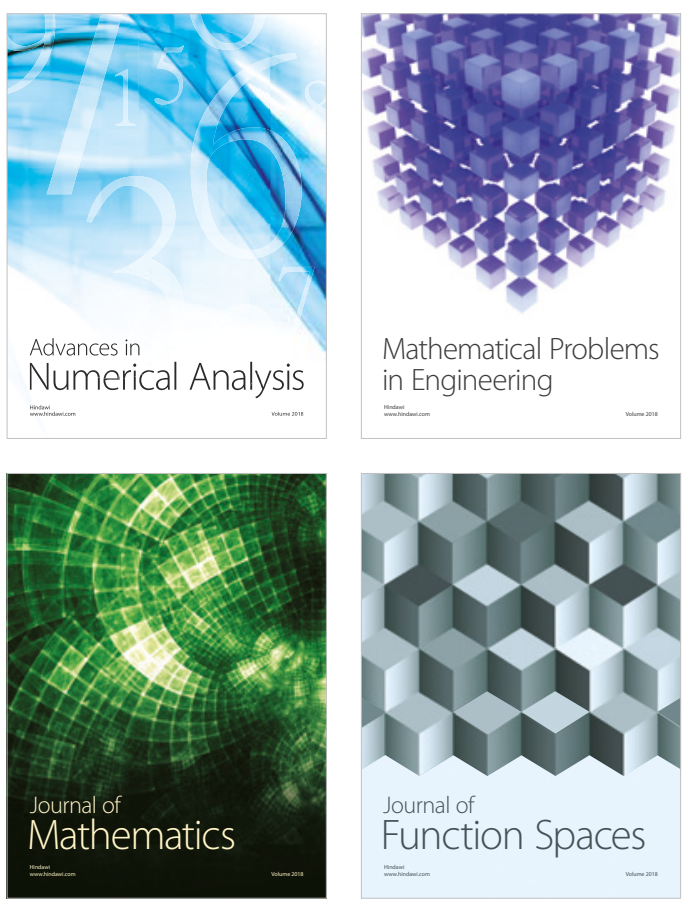

Mathematical Problems in Engineering

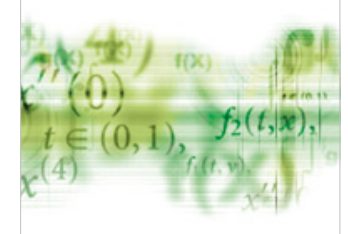

International Journal of

Differential Equations

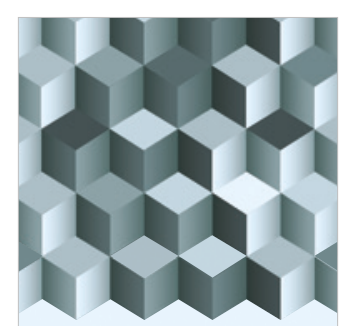

Journal of

Function Spaces

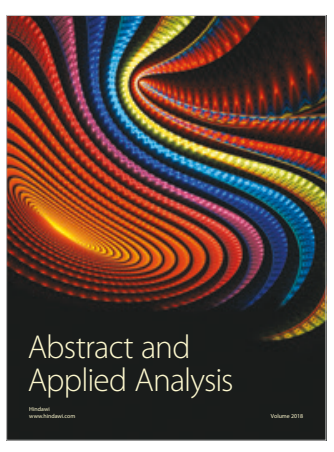

The Scientific

World Journal

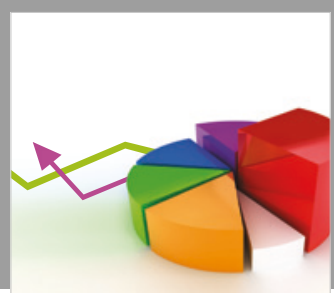

Journal of

Probability and Statistics
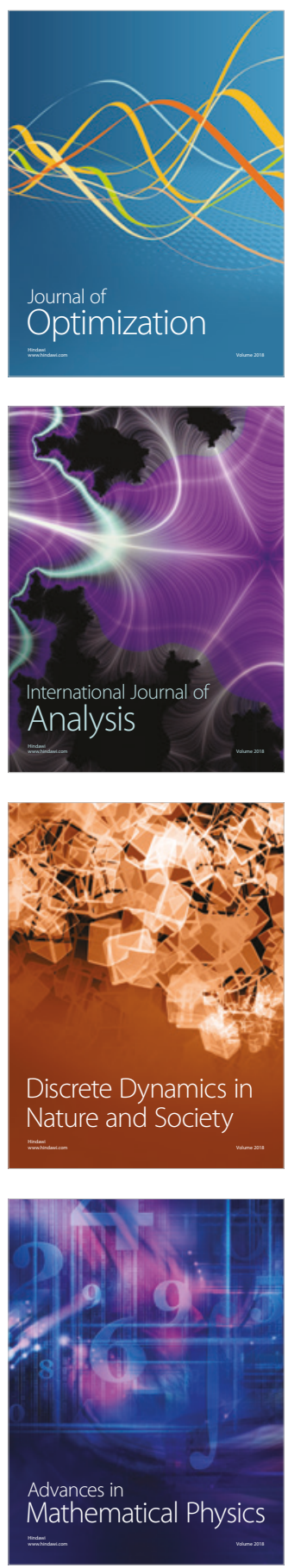